CLINICAL STUDY

\title{
Mortality and socioeconomic status in adults with childhood onset GH deficiency (GHD) is highly dependent on the primary cause of GHD
}

\author{
Kirstine Stochholm, Svend Juul ${ }^{1}$, Jens Sandahl Christiansen and Claus Højbjerg Gravholt \\ Department of Endocrinology and Internal Medicine, Aarhus University Hospital, NBG, Norrebrogade 44, DK-8000 Aarhus C, Denmark and ${ }^{1}$ Department \\ of Epidemiology, School of Public Health, Aarhus University, Aarhus C, Denmark \\ (Correspondence should be addressed to K Stochholm; Email: stochholm@dadlnet.dk)
}

\begin{abstract}
Objective: Childhood onset GH deficiency (CO-GHD) is associated with increased morbidity and mortality; however, the patients' socioeconomic profile as adults is not fully known.

Design: Register study using Danish nationwide registries. Two hundred and sixty GHD males and 156 GHD females and 25358 male and 15110 female controls were included.

Methods: Information was obtained concerning cohabitation, parenthood, education, income, retirement, convictions, and death. Income was analyzed using conditional logistic regression, and other outcomes were analyzed using Cox regression. Subgroups of GHD patients with malignant tumors, craniopharyngioma, idiopathic GHD, and others were investigated separately.

Results: Both male and female GHD patients had a significantly worse outcome on all studied socioeconomic parameters. Fewer GHD patients lived in partnerships and entered them later (male hazard ratio (HR): 0.31; female HR: 0.33), had fewer parenthoods (male HR: 0.26; female HR: 0.26), lower educational level (male HR: 0.58; female HR: 0.48), lower income, higher risk of retirement (male HR: 13.4; female HR: 24.2), and fewer convictions (male HR: 0.67; female HR: 0.49). Mortality was increased (male HR: 10.7; female HR: 21.4). Adjusted for marital and educational status, male HR of death was 5.2 and female HR 10.5. Patients with idiopathic GHD had a socioeconomic profile similar to controls.

Conclusion: The primary causes of CO-GHD and concomitant diseases severely impair socioeconomic conditions and impact mortality; only the subgroup of patients with idiopathic GHD conditions was similar to the background population.
\end{abstract}

European Journal of Endocrinology 167 663-670

\section{Introduction}

GH deficiency (GHD) has been recognized as a clinical entity for more than 40 years, with the clinical effect of treatment with $\mathrm{GH}$ reported (1) decades ago. The primary disease resulting in GHD has an impact on morbidity and mortality as shown previously in both hypopituitary $(2,3)$ and GHD populations $(4,5)$ as well as in selected subgroups $(6,7)$. The reports have been concordant regarding increased cardiovascular mortality, supported by clinical findings with impaired cardiovascular function in GHD patients, which improves upon $\mathrm{GH}$ treatment (8). The impact of $\mathrm{GH}$ treatment on morbidity and mortality is as yet unknown.

GHD can arise as the result of a wide spectrum of diseases (9). In questionnaire and interview studies, the consequences of childhood onset GHD (CO-GHD) on socioeconomic conditions $(10,11,12,13,14)$, psychological factors (15), and on quality of life (16) have been investigated, primarily in selected populations treated with GH. These studies compared GHD patients with controls or same sex siblings and identified an identical educational level, a reduced or identical employment degree, and a reduced number living with a partner. However, nonresponse may bias the results (17).

We investigated mortality and socioeconomic conditions in patients with CO-GHD, identified nationwide. They were matched on age and calendar time with controls using the unique Danish registries. We identified and compared their marital status, education, income, and retirement. Further, we analyzed mortality without and with adjustment for marital status and education.

\section{Materials and methods}

This study was designed as a classical cohort study. Exposed subjects were patients diagnosed with CO-GHD 
during 1970-1999 in Denmark (9), encompassing 303 males and 191 females. Their morbidity and mortality have previously been described in detail $(4,5)$. The following data include only those patients who were born between 1960 and 1991, and the sample was reduced to $260 \mathrm{GHD}$ males and $156 \mathrm{GHD}$ females who had reached adulthood before the end of follow-up in 2008. All patients were $<18$ years of age at the time of diagnosis, and the oldest patient was thus 48 years at the end of follow-up. Using Statistics Denmark, up to 100 new controls without a GHD diagnosis were randomly identified from the background population per GHD patient. The controls were matched on age (same year and month of birth) and gender. All controls were alive and living in Denmark at the time the patient was diagnosed with GHD. By this procedure 25358 male and 15110 female controls were identified.

\section{Socioeconomic outcome parameters}

From Statistics Denmark, we retrieved data regarding socioeconomic conditions, marital status, educational level, income, children, and retirement. We retrieved date of emigration, date of death, and the primary cause of death. These outcomes have been described in detail previously (18). None of the registries contain information regarding life style such as smoking habits, diet, or physical activity. We present information regarding cohabitation and marriage, education, income, parenthood, retirement, convictions, and mortality.

\section{Cohabitation and marriage}

We retrieved all persons' marital and cohabitational status, each on 1st of January. Data were available from 1980 through 2007. The event was first change from being single to cohabitating with a partner.

\section{Education}

Data were category of education and dates for achieved education. Educational categories registered were primary school, high school, vocational training, and a bachelor degree (e.g. laboratory technician or nurse). An achieved bachelor degree or higher was considered 'an education'. The event was the first achieved bachelor degree in a person between 18 and 40 years.

\section{Income}

Information on annual income, i.e. the taxable income before deductions, was given from 1980 to 2006. Only persons between 18 and 48 years of age with an income registered were included. As retired persons typically are on a fixed and reduced income, all retired persons were excluded from analysis from the year of retirement onwards.

\section{Parenthood}

All children born or adopted were registered until 2007 with a linkage to both of their registered parents.

\section{Retirement}

We defined retirement as due to age, sickness, and voluntary choice. A person was considered retired the first year money was received due to retirement and onwards, regardless of a later return to the labor market.

\section{Convictions}

In Denmark until 2010, the age of criminal responsibility was 15 years. All convictions have been electronically registered in the crime register since 1963. All convictions ever committed by a GHD patient or a control were retrieved from the crime register. We defined an event as the first conviction.

\section{Mortality}

For all analyses we used only the primary cause of death. We translated all diagnoses from ICD-8 to ICD-10 when necessary and categorized the deaths into the 19 chapters corresponding to ICD-10 for analyses of causespecific mortality. Hazard ratios (HRs) were calculated for each chapter and for all-cause mortality. Further, we adjusted for cohabiting status and education.

\section{Primary disease}

We divided all primary causes of GHD into four categories and analyzed the socioeconomic data in these separately. The four categories were malignant tumors, craniopharyngioma, idiopathic GHD, and others. The latter group of 'others' was by far the largest and consisted mainly of benign tumors, including pituitary adenomas, aplasia/hypoplasia of the pituitary, and trauma.

\section{Treatment with GH, irradiation, and operation; number of additional pituitary deficits}

We had information regarding these parameters with the latest possible registrations in 2002. We divided the GHD patients into those with and without known GH treatment. Number of additional deficits was defined as the sum of known deficits and/or relevant treatment for the given pituitary deficit.

\section{Adjustment}

We adjusted for cohabiting and educational status, both important protective factors regarding mortality $(19,20)$. 


\section{Statistical analysis}

The nonparametric test, Kruskall-Wallis, was used for the comparison of the median ages. The total number of persons was analyzed using Pearson's $\chi^{2}$.

Kaplan-Meier estimates were constructed for first experience of cohabitation, first education, first child, first conviction, and first retirement. Time at risk was calculated from the relevant birthday, 15 years (convictions and children), or 18 years (the others), or the date of start of registration, whichever came last, until the date of the first event, the date of emigration, the last date of registration, or 31 December 2008, whichever came first. HRs and $P$ values were calculated using Cox regression where each GHD patient and the matched controls were a stratum, hereby adjusting for age and calendar time. We analyzed mortality with and without adjustment for marital and educational status. The former was undertaken using marital and education status as time-dependent covariates.

Income was analyzed annually using conditional logistic regression, where each case and his/her matched controls were one stratum. Data are presented in 5-year intervals. The dependent variable was dichotomous, indicating whether the income was above or below the median income among controls in the 5-year interval. All odds ratios are shown as GHD patients compared with controls. The standard error reported is a robust standard error estimate, due to the clustering of data.

All results are shown with 95\% confidence intervals (CIs), or with range if relevant, and $P<0.05$ was considered statistically significant. We used Stata 11.0 (Stata Corp., College Station, TX, USA) for all calculations.

\section{Results}

Controls were identified for all GHD patients, and at least 84 controls were matched for every GHD patient. Both male and female GHD patients had a highly significant worse outcome on all studied socioeconomic variables (Table 1). Many fewer GHD patients entered a first partnership and this happened at an older age than controls (Fig. 1a and b and Table 1).

The HR among GHD patients compared with controls of achieving an education was 0.58 (95\% CI: $0.41-$ 0.81 ) for males and 0.48 (95\% CI: $0.32-0.72)$ for females. Twenty-three percent of males with GHD and $5 \%$ of their controls were registered with lower secondary school only or less; similar data was recorded for the females with $30 \%$ of the GHD patients and 5\% of the controls.

Income below the median was much more frequent among GHD patients, and this was evident from early adulthood into middle age (Fig. 2a and b).

The proportion of GHD males and females becoming parents was considerably lower than among controls (Fig. 3a and b). The HRs among males and females were similar. However, among those who attained parenthood, the age at first parenthood was similar among GHD patients and controls (Table 1). Early retirement was extremely frequent among GHD males (Fig. 4a) and even more frequent among GHD females in comparison with controls (Fig. 4b). By the age of 30, 2.9\% of the background population and $35.6 \%$ of the GHD males were retired. The corresponding figures for females were 2.4 and $40.3 \%$.

The risk of being convicted of a crime was reduced in GHD with a HR of 0.67 (95\% CI: $0.54-0.84)$ for males and a HR of 0.49 (95\% CI: 0.26-0.91) for females.

Table 1 Details regarding socioeconomic parameters and mortality among GH deficient patients and controls, divided into males and females. The percentages are calculated, excluding those without a registration, in each socioeconomic parameter. The various medians of age are only representative of those patients and controls registered with a first relevant registration, and are, as such, not informative of all who eventually later in life have a registration.

\begin{tabular}{|c|c|c|c|c|c|c|}
\hline & \multicolumn{3}{|c|}{ Males } & \multicolumn{3}{|c|}{ Females } \\
\hline & CO-GHD & Controls & $P$ value & CO-GHD & Controls & $P$ value \\
\hline Total number of persons & 260 & 25358 & & 156 & 15110 & \\
\hline Median age at diagnosis $(\mathrm{Cl})$ & $13.5(12.5-14.7)$ & - & & $12.5(11.2-13.5)$ & - & \\
\hline Median year of diagnosis $(\mathrm{Cl})$ & 1991 (1990-1992) & - & & 1991 (1990-1992) & - & \\
\hline Median year of birth $(\mathrm{Cl})$ & 1977 (1976-1979) & - & & $1978(1976-1980)$ & - & \\
\hline Number with relationship (\%) & $67(30.0)$ & $12506(58.5)$ & $<0.001$ & $56(41.2)$ & $8735(68.9)$ & $<0.005$ \\
\hline Median age at first relationship $(\mathrm{Cl})$ & $25.1(23.6-26.6)$ & $23.5(23.5-23.6)$ & $<0.001$ & $23.3(22.5-25.3)$ & $21.6(21.5-21.7)$ & $<0.0005$ \\
\hline $\begin{array}{l}\text { Number with at least one higher } \\
\text { education (\%) }\end{array}$ & $33(15.5)$ & $4960(23.7)$ & $<0.005$ & $23(17.4)$ & $3871(30.6)$ & $<0.001$ \\
\hline Retired persons (\%) & $68(26.5)$ & $638(2.6)$ & $<0.001$ & $48(31.8)$ & $332(2.2)$ & $<0.001$ \\
\hline Median age at retirement $(\mathrm{Cl})$ & $20.9(19.8-22.1)$ & $24.1(23.5-24.6)$ & $<0.0001$ & $20.9(19.3-22.0)$ & $26.3(24.8-27.8)$ & $<0.0001$ \\
\hline Number of fathers/mothers (\%) & $34(13.8)$ & $8822(37.1)$ & $<0.001$ & $29(19.7)$ & $6741(47.9)$ & $<0.001$ \\
\hline $\begin{array}{l}\text { Median age of fathers/mothers at birth } \\
\text { of first child }(\mathrm{Cl})\end{array}$ & $27(25-31)$ & $27(27-28)$ & 0.21 & $26(25-27)$ & $26(26-26)$ & 0.13 \\
\hline Number of deceased persons (\%) & $33(12.7)$ & $326(1.3)$ & $<0.001$ & $17(10.9)$ & $86(0.6)$ & $<0.001$ \\
\hline Median age of deceased persons $(\mathrm{Cl})$ & $20.7(15.7-25.8)$ & $25.9(24.7-26.9)$ & $<0.005$ & $18.8(12.5-27.2)$ & $26.8(23.1-29.8)$ & $<0.01$ \\
\hline
\end{tabular}

$\mathrm{Cl}$, confidence interval $(95 \%)$ 

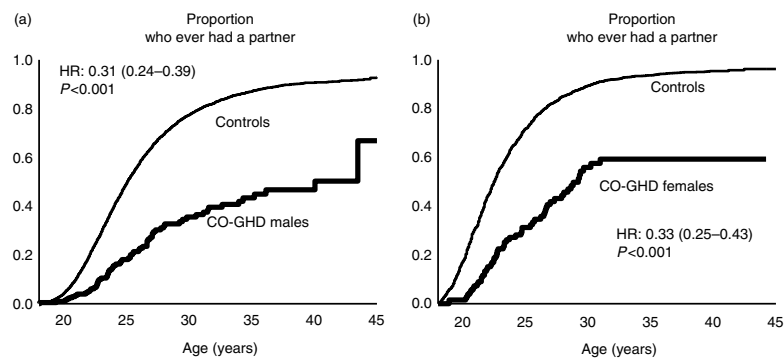

Figure 1 Proportion of GHD patients with partner. Kaplan-Meier plots demonstrating the proportion of GHD males (a) and females (b) (bold line) and their controls (thin line) registered with a partner for the first time.

There were distinct differences between the four larger groups of GHD causes (Table 2). Not surprisingly, the GHD groups of 'malignant tumors' and 'craniopharyngioma' had a very poor outcome on all parameters. In the small group of idiopathic GHD, results were insignificant and inconsistent. The remaining group of 'others' also had a consistently poorer outcome on all parameters.

We identified an excessively increased all-cause mortality of an HR of 10.7 (95\% CI: 7.5-15.4) for males, and a HR of 21.4 (95\% CI: 12.6-36.3) for females. When adjusting for marital and educational status, we identified substantial reductions to an HR of 5.2 (95\% CI: 3.5-7.6) for males and 10.5 (95\% CI: 5.7-19.1) for females. In the GHD population, 32 patients died due to cancer, of which $30(94 \%)$ were cancers related to the CNS. Of these 32 patients, $78 \%$ were CNS irradiated, $28 \%$ had pituitary operation, $41 \%$ received $\mathrm{GH}$ treatment, and $22 \%$ had a primary diagnosis of malignant cancer. By comparison, in the total GHD cohort $(n=416), 32 \%$ were CNS irradiated, $18 \%$ had pituitary operation, $76 \%$ received $\mathrm{GH}$ treatment, and $7 \%$ had a primary diagnosis of malignant cancer. Among the controls that died due to cancer, 19 out of $89(21 \%)$ died due to a CNS-related cancer. The 18 noncancer deaths in the GHD patients were due to various causes (see Fig. 5). There were no recorded deaths among patients with idiopathic GHD.

\section{Impact of treatment and other deficits}

Generally, the GHD patients who had been irradiated had a worse socioeconomic profile and an increased mortality, whereas the impact of pituitary operation was not clear. Those who had GH treatment generally had a better socioeconomic profile, and a reduced mortality. For the majority of the socioeconomic parameters, those who had more than two additional deficient pituitary axes had a worse socioeconomic profile (for details see Supplementary Table 1, see section on supplementary data given at the end of this article).

\section{Discussion}

This study shows a significantly increased socioeconomic burden in patients with CO-GHD when compared with an age-matched sample from the background population. When having CO-GHD, the chances of finding a partner or becoming a parent were severely impaired. Educational status, income, and retirement were all severely affected. The majority of socioeconomic parameters was deteriorated to similar levels in each of the three subgroups of patients with craniopharyngioma, malignant tumor, or other causes. This is in contrast to the subgroup of idiopathic GHD patients who were similar to the background population for all parameters except income.
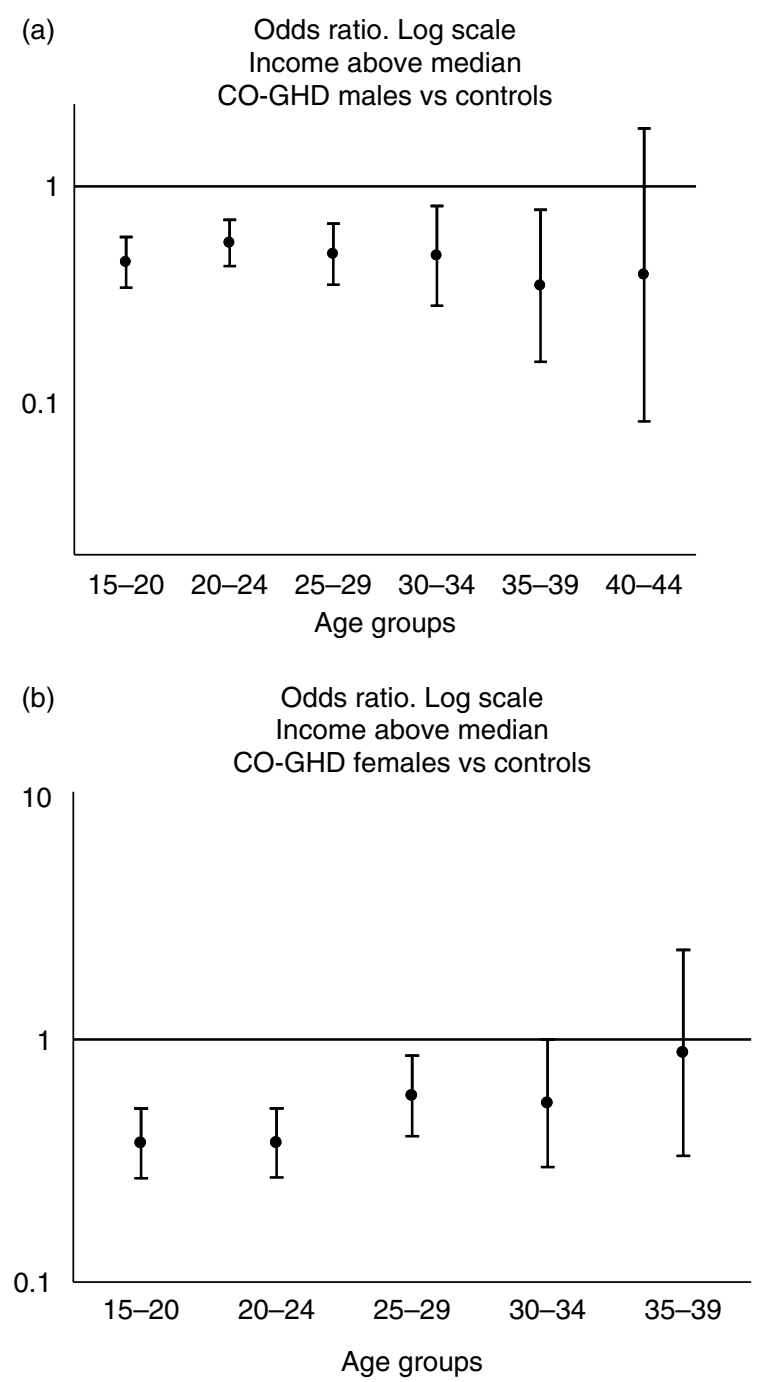

Figure 2 Odds ratio of income above median in GHD patients. GHD males (a) and females (b) vs controls. Per 5-year intervals of age, the median income was identified for each case's controls. All retired persons are excluded from being at risk from first year of registration of retirement. Note different scaling. 

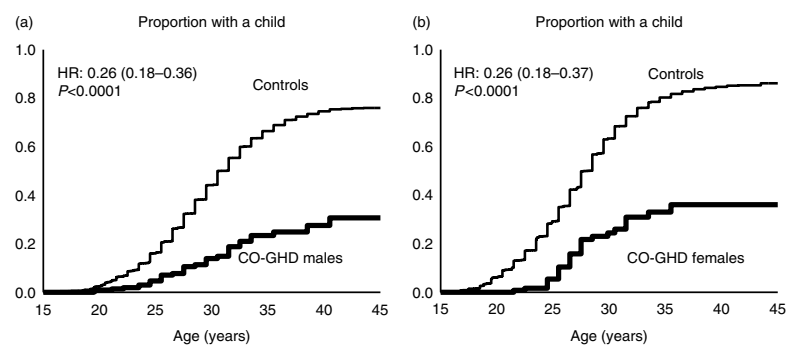

Figure 3 Proportion of GHD patients with a child. Kaplan-Meier plot of proportion of persons with a registration of firstborn child in GHD (a) males, (b) females (bold line), and controls (thin line).

We consider the significantly decreased proportion of GHD patients finding a partner a strong indicator of the impact on daily life. However, the data presented here do not readily explain why the GHD patients do not find a partner or do not become parents. It may be due to lack of interest or lack of hormonal drive, or due to the combined impact of low educational level and comorbidity that follow the primary disease (5). Similarly, the reduced number of children born to the GHD patients is not explained by the present design. We cannot determine whether it is the primary disease, the treatment, comorbidity, or the socioeconomic status which lead to the low fertility rate. However, we consider the hypopituitarism per se to be the most plausible cause of this finding. Previous data on marital status identified a reduced number of GHD patients with a partner compared with an expected age-adjusted rate $(10,12)$ and a reduced number of children born to GHD patients compared with controls (12). Furthermore, children with hypopituitarism and low stature have been shown to have difficulties with problem solving (21), often having to repeat a class, and have problems with adjustment (22), which may persist into adulthood and affect scholarly abilities. Impaired memory and motor skills have been reported in men with multiple pituitary deficiencies (23). Questionnaire studies assessing quality of life in different populations of adults with GHD have found reduced quality of life $(24,25,26,27,28)$.

The three subgroups of GHD patients with either well-defined primary diseases (i.e. cancer, craniopharyngioma) and idiopathic GHD were relatively small compared with the subgroup of 'others'; this group of 'others' includes a wide range of different rarer causes for developing GHD (9), and it is as such a rather inhomogeneous group of patients. Due to the close matching of patients and controls, we were able to calculate reliable HRs in all subgroups. It must be taken into consideration that the HRs identified in these subgroups, however, have relatively wide CIs; we suggest that most importance should be placed on the trend of the result, and not on the exact value. Here, we for the first time demonstrate that the consequences of idiopathic GHD seem to differ from the other categories, and that these patients fare reasonably well.

Previously, the cognitive function in children with constitutional short stature and short stature due to isolated GHD has been described as normal in most studies. In contrast, deficits have been identified in children with hypopituitarism as reviewed by Ross (29), which is in line with our findings of an educational level, which was significantly decreased both for boys and girls with GHD. Further, income was significantly reduced in both men and women with CO-GHD, possibly due to a cognitive dysfunction reducing the possibility to pursue a career. We also identified a low level of criminality among GHD patients, being significantly lower than among control persons. Generally the majority of convictions is present in the less educated part of the population, with a low income. However, we consider the reduced number of first-time convictions in GHD patients to be a consequence of a chronic disease.

The strength of this study includes the nationwide identification of GHD patients and their matched controls, and the use of register-based information. This minimizes the selection problems often found in studies requiring active participation. Furthermore, the patients were not selected on their out-patient clinic relationship, for instance a university hospital setting, and can be considered representative of the entire population of patients with a GHD diagnosis. The close matching of patients and controls enables us to undertake a statistically powerful comparison with the normal population, and ensures accounting for changes in socioeconomic conditions and mortality over time and with increasing age. The drawback is the lack of information regarding, for instance, quality of life and intelligence.

Mortality in a larger GHD cohort has been described previously (4) where the HR for males was 8.3 (95\% CI: 4.5-15.1) and for females 9.4 (95\% CI: 4.6-19.4), adjusted for age. This study includes only patients born between 1960 and 1991; however, the controls were identified using the same criteria but are now expanded from five to 100 per patient. Furthermore, the dates for the causes of deaths are extended from December 2001
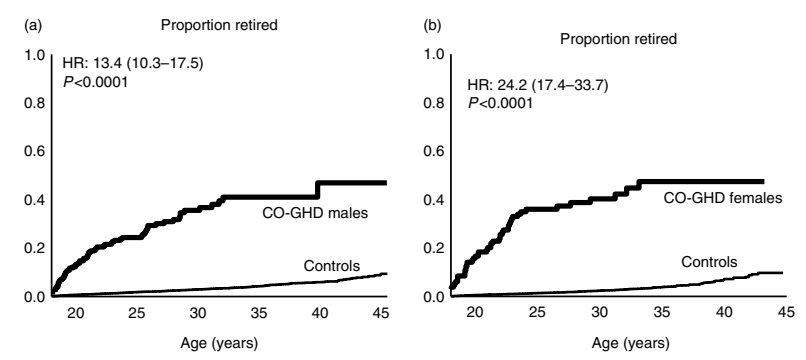

Figure 4 Proportion GHD patients who retired. The proportion of GHD (a) males, (b) females (bold line), and controls (thin line) with a first registration of retirement (for details see Materials and methods). 
Table 2 Hazard ratios (HRs) for socioeconomic parameters in GH deficient patients $(n=416)$ compared with controls $(n=40468)$. HRs for the socioeconomic parameters divided into the four main diagnostic groups (for details, see Materials and methods section). HR not available due to lack of events. In parentheses $95 \%$ confidence intervals are presented.

\begin{tabular}{|c|c|c|c|c|}
\hline & Malignant tumors & Craniopharyngeoma & $\begin{array}{l}\text { Idiopathic GH } \\
\text { deficiency }\end{array}$ & Others \\
\hline \multicolumn{5}{|c|}{ Number of CO-GHD persons } \\
\hline Males & 16 & 25 & 35 & 184 \\
\hline Females & 14 & 16 & 15 & 111 \\
\hline \multicolumn{5}{|l|}{ Partnership } \\
\hline Males & $0.13(0.03-0.52)$ & $0.16(0.05-0.50)$ & $0.71(0.43-1.17)$ & $0.29(0.22-0.38)$ \\
\hline Females & $0.28(0.09-0.87)$ & $0.30(0.11-0.80)$ & $0.52(0.27-1.01)$ & $0.31(0.23-0.42)$ \\
\hline \multicolumn{5}{|l|}{ Education } \\
\hline Males & $0.22(0.03-1.60)$ & $0.66(0.21-2.05)$ & $0.93(0.44-1.96)$ & $0.54(0.36-0.82)$ \\
\hline Females & - & $0.55(0.14-2.21)$ & $0.36(0.09-1.43)$ & $0.56(0.36-0.88)$ \\
\hline \multicolumn{5}{|l|}{ Children } \\
\hline Males & $0.13(0.02-0.89)$ & $0.08(0.01-0.56)$ & $0.45(0.20-1.01)$ & $0.26(0.18-0.38)$ \\
\hline Females & $0.32(0.08-1.30)$ & - & $0.75(0.36-1.59)$ & $0.23(0.15-0.36)$ \\
\hline \multicolumn{5}{|l|}{ Retirement } \\
\hline Males & $15.3(5.3-44.2)$ & $30.0(14.2-63.2)$ & $1.61(0.22-11.66)$ & $13.9(10.3-18.8)$ \\
\hline Females & $105.7(35.5-314.6)$ & $21.5(7.2-64.0)$ & $3.55(0.48-26.28)$ & $24.9(16.9-36.6)$ \\
\hline \multicolumn{5}{|l|}{ Mortality } \\
\hline Males & $34.3(12.2-96.4)$ & 16.9 (6.5-43.9) & - & $10.2(6.7-15.8)$ \\
\hline Females & $92.5(26.8-319.9)$ & $15.0(3.4-67.2)$ & - & $18.5(9.4-36.7)$ \\
\hline
\end{tabular}

to December 2006 for the cause-specific information and from December 2004 to December 2008 for total mortality. Thus, the advantage is a greater number of events, and the increased numbers of controls enhance the possibility to identify rare events. We have recently presented socioeconomic and mortality data on patients with Klinefelter syndrome and in comparison the impact of the primary cause of hypopituitarism/GHD must be seen as more severe on all studied aspects (18), and likewise the impact on mortality is more severe than seen among patients with Turner syndrome $(30,31)$, which emphasizes that CO-GHD is a very severe condition, with the important exception of the small group with idiopathic GHD which do better than the other GHD groups. The latter finding is positive indeed and expected pathogenetically, due to the absence of concomitant illnesses, with regards to the GHD diagnosis. These patients might have normal GH secretion at retesting after achievement of final height; however, we have no information regarding this aspect.

The subgroup of patients who died due to cancer had other baseline characteristics compared with the other patients. We therefore hypothesize that the cancer deaths among the GHD patients more likely are due to their primary disease combined with irradiation, and not because of the GH treatment they received. Only two of the cancer deaths were (possibly) unrelated to cancer of the CNS, namely one death due to unspecified malignancy of the bronchus or lung and the other was an unspecified cancer death.

When adjusting for marital status and education, the mortality ratios decreased. The adjusted estimates should not be considered more correct than the unadjusted estimates; but the finding rather reflects that CO-GHD affects physical and mental development, with a combination of social consequences as well as consequences for mortality.

In conclusion, we identified severe socioeconomic consequences for patients with CO-GHD compared with age- and calendar-time matched controls. The consequences are present in marital status, number of
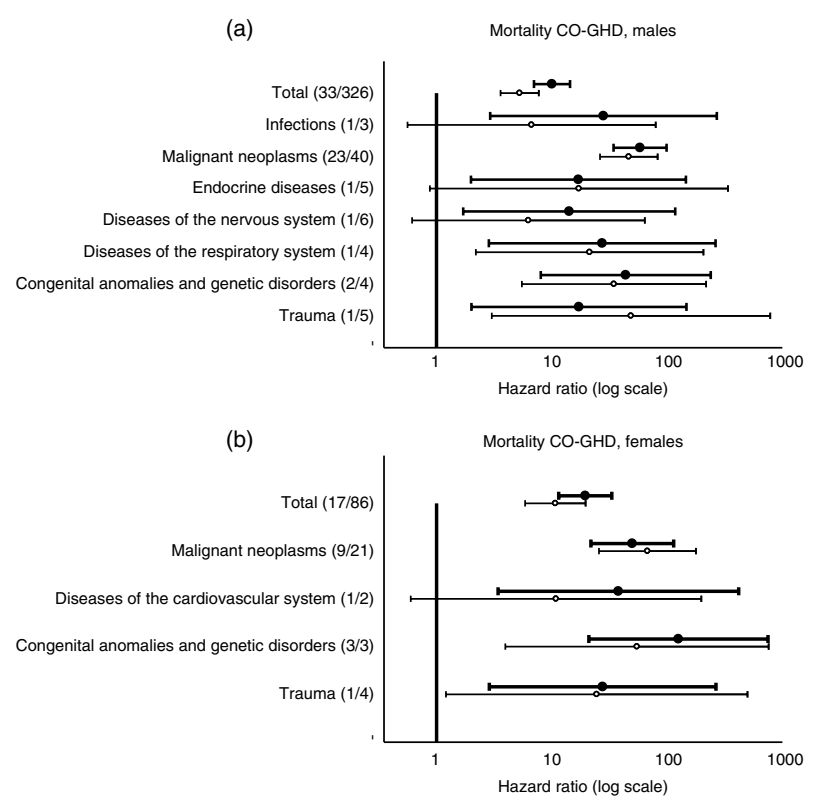

Figure 5 Mortality in GHD patients. All-cause and cause-specific HRs of mortality in GHD males (a) and females (b) compared with controls (bold line), and mortality ratios adjusted for marital status and education (thin line). Numbers in parentheses indicate number of deceased persons, GHD patients, and controls, respectively. Only informative chapters are included. Note log-scale on the $X$-axis. 
children, education, income, and retirement in both genders. Based on these findings, evaluation of socioeconomic circumstances should be a part of the routine clinical management in GHD children; however, we are not able to identify specific solutions to these problems.

\section{Supplementary data}

This is linked to the online version of the paper at http://dx.doi.org/10. 1530/EJE-11-1084.

\section{Declaration of interest}

The authors declare that there is no conflict of interest that could be perceived as prejudicing the impartiality of the research reported.

\section{Funding}

$\mathrm{K}$ Stochholm was supported by a research grant from Central Denmark Region (grant number: 1-45-72-7-07) and from the Danish Ministry of Science, Technology and Innovation (grant number: 217-08-0907).

\section{Author contribution statement}

$\mathrm{K}$ Stochholm made substantial contributions to conception and design, as well as analysis, interpretation of data, and drafted the manuscript. S Juul made contributions to conception and design, interpretation of data, and revised it critically. J S Christiansen and C H Gravholt made substantial contributions to conception and design, interpretation of data, and revised it critically. All authors have given final approval of the version to be published.

\section{Acknowledgements}

Novo Nordisk A/S is thanked for the unrestricted research grant, when K Stochholm identified the GHD cohort.

\section{References}

1 Raben M. Growth hormone. 2. Clinical use of human growth hormone. New England Journal of Medicine 1962266 82-86. (doi:10.1056/NEJM196201112660207)

2 Svensson J, Bengtsson BA, Rosen T, Oden A \& Johannsson G. Malignant disease and cardiovascular morbidity in hypopituitary adults with or without growth hormone replacement therapy. Journal of Clinical Endocrinology and Metabolism $2004 \mathbf{8 9}$ 3306-3312. (doi:10.1210/jc.2003-031601)

3 Tomlinson JW, Holden N, Hills RK, Wheatley K, Clayton RN, Bates AS, Sheppard MC \& Stewart PM. Association between premature mortality and hypopituitarism. West Midlands Prospective Hypopituitary Study Group. Lancet 2001357 425-431. (doi:10.1016/S0140-6736(00)04006-X)

4 Stochholm K, Gravholt C, Laursen T, Laurberg P, Andersen M, Kristensen L, Feldt-Rasmussen U, Christiansen J, Frydenberg M \& Green A. Mortality in growth hormone deficiency - a nationwide study. European Journal of Endocrinology $2007 \quad 157$ 9-18. (doi:10.1530/EJE-07-0013)

5 Stochholm K, Laursen T, Green A, Laurberg P, Andersen M, Kristensen L, Feldt-Rasmussen U, Christiansen S, Frydenberg M \& Gravholt C. Morbidity and GH deficiency: a nationwide study. European Journal of Endocrinology $2008 \mathbf{1 5 8}$ 447-457. (doi:10.1530/EJE-07-0523)
6 Bulow B, Attewell R, Hagmar L, Malmstrom P, Nordstrom CH \& Erfurth EM. Postoperative prognosis in craniopharyngioma with respect to cardiovascular mortality, survival, and tumor recurrence. Journal of Clinical Endocrinology and Metabolism $1998 \mathbf{8 3}$ 3897-3904. (doi:10.1210/jc.83.11.3897)

7 Erfurth EM, Bulow B, Svahn-Tapper G, Norrving B, Odh K, Mikoczy Z, Bjork J \& Hagmar L. Risk factors for cerebrovascular deaths in patients operated and irradiated for pituitary tumors. Journal of Clinical Endocrinology and Metabolism 200287 4892-4899. (doi:10.1210/jc.2002-020526)

8 Colao A, Di Somma C, Cuocolo A, Filippella M, Rota F, Acampa W, Savastano S, Salvatore M \& Lombardi G. The severity of growth hormone deficiency correlates with the severity of cardiac impairment in 100 adult patients with hypopituitarism: an observational, case-control study. Journal of Clinical Endocrinology and Metabolism 200489 5998-6004. (doi:10.1210/ jc.2004-1042)

9 Stochholm K, Gravholt C, Laursen T, Jorgensen JO, Laurberg P, Andersen M, Kristensen L, Feldt-Rasmussen U, Christiansen J, Frydenberg $M$ \& Green A. Incidence of $\mathrm{GH}$ deficiency - a nationwide study. European Journal of Endocrinology $2006 \mathbf{1 5 5}$ 61-71. (doi:10.1530/eje.1.02191)

10 Dean H, McTaggart T, Fish D \& Friesen H. The educational, vocational, and marital status of growth hormone-deficient adults treated with growth hormone during childhood. American Journal of Diseases of Children 1985139 1105-1110.

11 Galatzer A, Aran O, Beit-Halachmi N, Nofar E, Rubitchek J, Pertzelan A \& Laron Z. The impact of long-term therapy by a multidisciplinary team on the education, occupation and marital status of growth hormone deficient patients after termination of therapy. Clinical Endocrinology 198727 191-196. (doi:10.1111/j. 1365-2265.1987.tb01144.x)

12 Rikken B, van Busschbach J, le Cessie S, Manten W, Spermon T, Grobbee R \& Wit J. Impaired social status of growth hormone deficient adults as compared to controls with short or normal stature. Dutch Growth Hormone Working Group. Clinical Endocrinology 199543 205-211. (doi:10.1111/j.1365-2265. 1995.tb01916.x)

13 Takano K, Tanaka T \& Saito T. Psychosocial adjustment in a large cohort of adults with growth hormone deficiency treated with growth hormone in childhood: summary of a questionnaire survey. Committee for the Study Group of Adult GH Deficiency. Acta Paediatrica. Supplement 1994399 16-19. (doi:10.1111/ j.1651-2227.1994.tb13278.x)

14 Keselman A, Martinez A, Pantano L, Bergada C \& Heinrich JJ. Psychosocial outcome in growth hormone deficient patients diagnosed during childhood. Journal of Pediatric Endocrinology $\mathcal{E}$ Metabolism 200013 409-416. (doi:10.1515/JPEM.2000. 13.4.409)

15 Frisch H, Hausler G, Lindenbauer S \& Singer S. Psychological aspects in children and adolescents with hypopituitarism. Acta Paediatrica Scandinavica 199079 644-651. (doi:10.1111/j.16512227.1990.tb11529.x)

16 Sandberg D, Gillivray MH, Clopper RR, Fung C, LeRoux L \& Alliger DE. Quality of life among formerly treated childhood-onset growth hormone-deficient adults: a comparison with unaffected siblings. Journal of Clinical Endocrinology and Metabolism $1998 \mathbf{8 3}$ 1134-1142. (doi:10.1210/jc.83.4.1134)

17 Edwards PJ, Roberts I, Clarke MJ, Diguiseppi C, Wentz R, Kwan I, Cooper R, Felix LM \& Pratap S. Methods to increase response to postal and electronic questionnaires. Cochrane Database of Systematic Reviews 20098 1-481. (doi:10.1002/14651858. MR000008.pub4)

18 Bojesen A. Stochholm K, Juul S \& Gravholt CH. Socioeconomic trajectories affect mortality in Klinefelter syndrome. Journal of Clinical Endocrinology and Metabolism $2011962098-2104$. (doi:10.1210/jc.2011-0367)

19 Rendall MS, Weden MM, Favreault MM \& Waldron H. The protective effect of marriage for survival: a review and update. Demography 201148 481-506. (doi:10.1007/s13524-011-0032-5) 
20 Cutler DM, Lange F, Meara E, Richards-Shubik S \& Ruhm CJ. Rising educational gradients in mortality: the role of behavioral risk factors. Journal of Health Economics 201130 1174-1187. (doi:10.1016/j.jhealeco.2011.06.009)

21 Drotar D, Owens R \& Gotthold J. Personality adjustment of children and adolescents with hypopituitarism. Child Psychiatry and Human Development 198011 59-66. (doi:10.1007/BF00 705871)

22 Holmes CS, Thompson RG \& Hayford JT. Factors related to grade retention in children with short stature. Child: Care, Health and Development 198410 199-210. (doi:10.1111/j.1365-2214. 1984.tb00179.x)

23 Baum HB, Katznelson L, Sherman JC, Biller BM, Hayden DL, Schoenfeld DA, Cannistraro KE \& Klibanski A. Effects of physiological growth hormone $(\mathrm{GH})$ therapy on cognition and quality of life in patients with adult-onset GH deficiency. Journal of Clinical Endocrinology and Metabolism $1998 \quad 83$ 3184-3189. (doi:10.1210/jc.83.9.3184)

24 McGauley GA. Quality of life assessment before and after growth hormone treatment in adults with growth hormone deficiency. Acta Paediatrica Scandinavica. Supplement 1989356 70-72. (doi:10.1111/j.1651-2227.1989.tb11249.x)

25 Burman P, Broman JE, Hetta J, Wiklund I, Erfurth EM, Hagg E \& Karlsson FA. Quality of life in adults with growth hormone (GH) deficiency: response to treatment with recombinant human GH in a placebo-controlled 21-month trial. Journal of Clinical Endocrinology and Metabolism 199580 3585-3590. (doi:10.1210/jc.80.12.3585)
26 Rosen T, Wiren L, Wilhelmsen L, Wiklund I \& Bengtsson BA. Decreased psychological well-being in adult patients with growth hormone deficiency. Clinical Endocrinology 199440 111-116. (doi:10.1111/j.1365-2265.1994.tb02452.x)

27 Wiren L, Whalley D, McKenna S \& Wilhelmsen L. Application of a disease-specific, quality-of-life measure (QoL-AGHDA) in growth hormone-deficient adults and a random population sample in Sweden: validation of the measure by rasch analysis. Clinical Endocrinology 200052 143-152. (doi:10.1046/j.1365-2265.2000.00899.x)

28 Badia X, Lucas A, Sanmarti A, Roset M \& Ulied A. One-year follow-up of quality of life in adults with untreated growth hormone deficiency. Clinical Endocrinology 199849 765-771. (doi:10.1046/j.1365-2265.1998.00634.x)

29 Ross JL. Effects of growth hormone on cognitive function. Hormone Research in Paediatrics 200564 89-94. (doi:10.1159/000089323)

30 Stochholm K, Hjerrild B, Mortensen K, Juul S, Frydenberg M \& Gravholt C. Socio-economic parameters and mortality in Turner syndrome. European Journal of Endocrinology 2012166 1013-1019. (doi:10.1530/EJE-11-1066)

31 Schoemaker MJ, Swerdlow AJ, Higgins CD, Wright AF \& Jacobs PA. Mortality in women with Turner syndrome in Great Britain: a national cohort study. Journal of Clinical Endocrinology and Metabolism 200893 4735-4742. (doi:10.1210/jc.2008-1049)

Received 21 December 2011

Revised version received 16 August 2012

Accepted 23 August 2012 